\title{
Editorial \\ Consilience in Action: Lessons from an International Childhood Trauma Conference
}

\author{
Joe Tucci ${ }^{1}$ and Janise Mitchell ${ }^{2}$ \\ ${ }^{1}$ CEO, Australian Childhood Foundation, PO Box 525, Ringwood VIC 3134, Australia \\ E-mail: jtucci@childhood.org.au \\ ${ }^{2}$ Deputy CEO, Australian Childhood Foundation, PO Box 525, Ringwood VIC 3134, Australia \\ E-mail: jmitchell@childhood.org.au
}

In August 2014, the Australian Childhood Foundation ran a conference on childhood trauma using a unique format. We gathered together a range of the world's master knowledgebuilders in the field of interpersonal neurobiology. We asked them to explore themes that were relevant to the ways in which those affected by trauma could heal through connection and care.

The emergent conversations wove together rich reflections about hard science, therapeutic practice and the ways through which both meaning and intersubjectivity come to be experienced in relationships that shape and reshape the reactions of children, young people and adults forced to live with violence and abuse.

This edition of Children Australia is a collection of papers from our keynote speakers drawn from their conference presentations. Together, they form a snapshot of current interpretations of ourfield of endeavour in models of support and care for children and young people. Many of the authors have highlighted how neuroscience offers a framework for understanding and action that serves to integrate children's right to safety with therapeutic and sometimes political responses that offer the hope of transformation. All of them thread through their work a commitment to protecting children from violence, abuse, neglect and the trauma resulting from these experiences.

Setting the scene, Cindy Blackstock provides a powerful exposé of the ongoing discrimination against First Nations children in Canada, embedded in both past and current government policies. Cindy's accounts of Indigenous children being beaten and punished in electric chairs within the very institutions given the responsibility by the State to look after them draw direct parallels with the evidence presented in the Australian Senate Inquiry about the Stolen Genera-

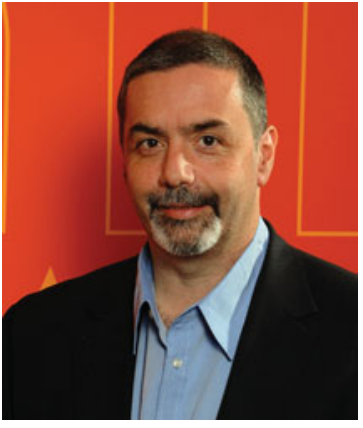

tion and the current Royal Commission into Institutional Responses to Child Sexual Abuse. Moreover, the legal challenge Cindy has led through the First Nations Child and Family Caring Society against the Canadian Government is a reminder that the challenge to keep children safe from the trauma of violence requires concerted and unwavering collective action, despite its personal and organisational costs.

Allan Schore's opening plenary marked the 20th anniversary of the publication of the seminal Affect regulation and the origin of the self (first published in 1994). In his paper for this edition, he traces the evolution of the integration of neuroscience into the practice of psychotherapy through a journey of appreciation of the function of the right hemisphere as the site of human attachment and connection. Allan's scholarship and meticulous attention to evidence locates his analysis and commentary as a benchmark in this field. So when he says there is a paradigm shift in the focus of therapeutic practice from '... behaviour, to cognition, to bodily-based emotion, and from the language functions 
of the left brain to the emotional functions of the right brain ...', we should pay attention.

Steve Porges summarises the relevance of his Polyvagal Theory to understanding our inherent biological drive for safety in connectedness with others. His basic tenant emphasises just how critical relationships are to calming and co-regulating the neural defence systems activated by social and environmental cues of threat and terror. Steve also offers us a revision of evolutionary survival perhaps not being as rooted in competitive, territorial and aggressive behaviour as we have been led to assume but more likely to stem from adaptations that have promoted '... gentleness and cooperation ...? This is a worldview that offers children intimacy as the source for the development of resilience through strengthening the capacity of their social engagement system to open themselves to the sounds and felt experiences of safety. Steve shows his magical capacity to explain and inspire simultaneously through the clarity of his conceptualisation.

Ed Tronick and Jennifer Di Corcia apply the easy to understand metaphor of building stamina through repeated training to run a marathon to aid our understanding of how infants build resilience to stress. Their work is critical to all of us who work with aroused and dysregulated children. For them, disorganised neurobiological systems are an intrinsic part of growing up. It is normal. Transitions and change are a challenge for the developing child, but they are also normal and inevitable. The responses children receive at these challenging times build, over time, the child's capacity for internalised systems of self-repair and adaptation. Using decades of research, Ed and Jennifer highlight the kind of caregiver responses that are effective and, conversely, those that can cause children to deteriorate. This is the evidence base that underpins the evolution of effective models of therapeutic care for children in out-of-home care. It offers caregivers the skills and knowledge that can be used to help them to provide attuned and co-regulatory support to their child's stressed physiological system. Repeated exposure to such care provides children with cascading positive effects that are sustainable over time.

In each of the three consecutive papers by Pat Ogden, Dan Hughes and Kim Golding, the work of researchers and theorists has been translated into practical applications to support and create opportunities for improvements in the lives of traumatised children, young people and their carers and/or families. Pat offers an elegant framework to understand and interpret the experiences of proximity, defence and boundaries between and around children and their care givers. As would be expected in Pat's work, the body and its interaction with others and the meaning that can be derived by its actions and reactions are sensitively woven into an approach that resonates deeply as you read it.

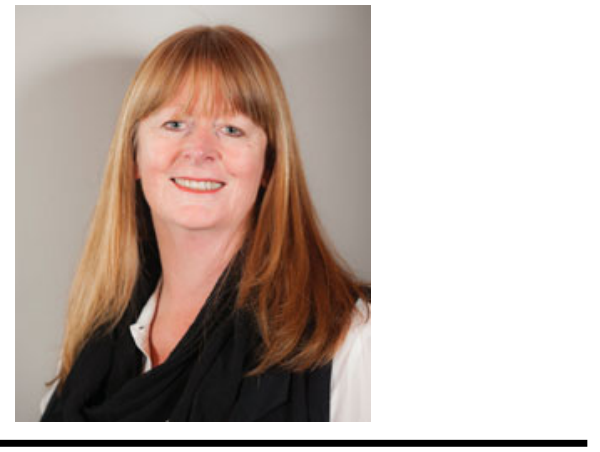

Dan, of course, is a classic story teller who weaves the child-centred playful orientation of his approach with traumatised children and their carers into a modern fable about the experience of intersubjectivity being the pivotal quality in the connections that promote growth for children. Similarly, Kim shares one of the pillars of her practice that has come to be a mantra for foster carers, adoptive carers and residential carers the world over. 'Connection before correction' highlights the importance of keeping the significance of the relationship with traumatised children at the forefront of all parenting and disciplinary strategies.

The framework of consilience (the act of distilling the universal findings from independent schools or disciplines of knowledge building) offered by Dan Siegel is a natural conclusion to the edition. In his paper, Dan masterfully revisits the very basis of the field of interpersonal neurobiology. In a whirlwind of 18 basic principles, Dan captures definitions for the mind, relationships and mental health that are an invaluable guide to us as we endeavour to help and support individuals suffering from trauma. There also emerges a valuable guide to ease the stress that often accompanies this task.

The conference embraced participants, presenters and organisers in a community that felt real and supportive. It offered a sense of collective purpose that, as a field, we are trying to understand the nature of trauma, its effects and what can work to transform it. In this collection of papers, that same ambition percolates, with the possibility of knowing more and feeling more of each other in such commitment.

Our second conference, planned for 6-10 June 2016 in Melbourne, blends these authors with a new line-up that will trace new developments in relational, body-oriented and brain-based approaches to recovery and change for those affected by childhood trauma www.childtraumaconf.org. We look forward to seeing you then. 